\title{
Temperature-Modified Acute Effects of Ozone on Human Mortality - Beijing Municipality, Tianjin Municipality, Hebei Province, and Surrounding Areas, China, 2013-2018
}

\author{
Chen Chen ${ }^{1}$; Jing Liu ${ }^{1}$; Wanying Shi ${ }^{1}$; Tiantian $\mathrm{Li}^{1}$; Xiaoming Shi ${ }^{1, \text { t, }}$
}

\section{Summary}

What is already known about this topic?

Ozone $\left(\mathrm{O}_{3}\right)$ is a weather-driven photochemical ambient pollutant, and its harm to human health may be affected by meteorological factors such as temperature. However, there is conflicting evidence regarding whether temperature can modify the effects of ozone on health.

\section{What is added by this report?}

Short-term exposure to $\mathrm{O}_{3}$ in the Beijing Municipality, Tianjin Municipality, Hebei Province, and surrounding areas was associated with an increased risk of human mortality and that association was positive modified by relatively higher ( $>75$ th 24 h-average temperature) or extreme cold temperature $(<10$ th $24 \mathrm{~h}$ average temperature). Under extreme temperatures ( $>90$ th 24 h-average temperature) modification, the associations were further increased. Cardiopulmonary diseases, as vulnerable diseases of air pollution, their mortality risks associated with $\mathrm{O}_{3}$ were markedly strengthened by uncomfortable temperatures.

What are the implications for public health practice?

This study suggests that policymakers should pay attention to the synergistic effect between ozone and heat or extreme cold on human health, as well as provide evidence for establishing an integrated earlywarning system to protect the public against both uncomfortable temperature and air pollution.

Short-term exposure to ambient ozone $\left(\mathrm{O}_{3}\right)$, a weather-driven photochemical pollutant, has been found to be associated with increased risk of mortality in previous epidemiological studies (1-2). Most of these studies analyzed $\mathrm{O}_{3}$-mortality associations by controlling for meteorological factors in a model fitting process. Regarding the high correlation between $\mathrm{O}_{3}$ and temperature, a recent area of interest is whether the observed $\mathrm{O}_{3}$-mortality associations can be modified by temperature. Jhun et al. found both high and low temperature could strengthen acute effects of $\mathrm{O}_{3}$ on mortality (3), while Chen et al. and Shi et al. reported that $\mathrm{O}_{3}$-mortality associations were strengthened in high temperature but not in low temperature settings (4-5), and Liu et al. and Chen et al. only found modifications by low temperature (6-7). In summary, evidence on temperature-modification was inconsistent and needed to be supplemented by regional epidemiological studies involving various meteorological characteristics. Note that in the new air quality guidelines issued by the World Health Organization (WHO), $\mathrm{O}_{3}$ limits have been distinguished between warm and cold seasons. Beijing Municipality and Tianjin Municipality, along with 26 cities distributed in Hebei, Shandong, Shanxi and Henan Provinces, have formed the regional air pollution transmission channel, and experienced a challenge of regional $\mathrm{O}_{3}$ pollution increasing steadily. Therefore, additional efforts are needed to better quantify the local health risks of $\mathrm{O}_{3}$ by considering the influence of temperature in the Beijing, Tianjin, Hebei and surrounding areas.

This study used daily counts of deaths from the Disease Surveillance Point System of China CDC and included 39 counties in the Beijing, Tianjin, Hebei and surrounding areas from January 1, 2013 to December 31, 2018. Three major causes of deaths were classified according to the 10th Revision of the International Statistical Classification of Diseases (ICD-10): non-accidental disease (A00-R99), cardiocerebrovascular disease (I00-I99), and respiratory disease (J00-J99). Daily ambient $\mathrm{O}_{3}$ concentrations were collected from the National Urban Air Quality Real-Time Release Platform and calculated to a daily 8-hour moving average maximum $\left(\mathrm{O}_{3} 8 \mathrm{~h}\right.$-average $), 1$ hour maximum $\left(\mathrm{O}_{3} 1 \mathrm{~h}\right.$-max $)$, and 24 hour-average of $\mathrm{O}_{3}\left(\mathrm{O}_{3} 24\right.$ h-average $)$. Daily average temperature and relative humidity were obtained from the China Meteorological Data Network.

The study applied two time-series approaches with a two-stage statistical analysis to estimate whether and how temperature modified acute effects of $\mathrm{O}_{3}$ on 
mortality in the Beijing, Tianjin, Hebei and surrounding areas. The first approach, a temperatureadjusted approach, aimed to control the cumulative temperature impacts with a cross-basis function using a generalized linear model (GLM) and analyze associations between $\mathrm{O}_{3}$ and death without considering interactions.

The second approach, a temperature-stratified approach by a Pick-A-Point technique centering on changes of the conditional effect of $\mathrm{O}_{3}$ across the designated levels of the modifier (8), aimed to construct interaction terms between $\mathrm{O}_{3}$ and a stratification variable of temperature in the GLM and analyze differences of associations under three different temperature levels: low, moderate, and high temperature. In this model, we used three cutoffs to categorize daily average temperature, including the 10th and 90th $\left(\mathrm{P}_{10} / \mathrm{P}_{90}\right)$, 20th and 80th $\left(\mathrm{P}_{20} / \mathrm{P}_{80}\right)$, and 25th and 75 th $\left(\mathrm{P}_{25} / \mathrm{P}_{75}\right)$ percentiles. The model of the temperature-stratified approach was set up as follows:

$$
\begin{aligned}
\log \left[E\left(Y_{t}\right)\right]= & \text { intercept }+\beta O_{3}+\beta_{1} \text { Tem }+\beta_{2}\left(O_{3}: \text { Temstrata }\right) \\
& +n s(R H, d f)+d o w+n s(\text { time }, d f)
\end{aligned}
$$

Where was the expected value of death on day $\mathrm{t}$; Tem represented the daily value of temperature; $\left(\mathrm{O}_{3}:\right.$ Temstrata $)$ was the interaction term between $\mathrm{O}_{3}$ and temperature, in which temperature was divided into low, moderate, and high levels of the categorical variable by cutoffs. Both approaches estimated effects of the 2-day average of current and previous-day concentrations (lag 01) of $\mathrm{O}_{3} 8$ h-average and controlled for seasonal and time trends [time, natural smoothing function of 8 degrees of freedom $(d f)]$, day of the week $(d o w)$, and relative humidity $(R H$, natural smoothing function of $5 d f$ ). The effect estimate was expressed as a percent increase (PI) in mortality risk per $10 \mu \mathrm{g} / \mathrm{m}^{3}$ increase in $\mathrm{O}_{3}$ exposure.
This study examined the sensitivity of key findings for non-accidental mortality with respect to using the following: 1) the specification of $d f$ in the smoothing functions of time trend ( $d f=6$ or $7 /$ year) and relative humidity $(d f=3)$ in the temperature-adjusted approach to observe model stability; 2) the other two metrics $\left(\mathrm{O}_{3} 1 \mathrm{~h}\right.$-max and $\mathrm{O}_{3} 24$ h-average $)$ with different lagged exposure [the same day as deaths (lag 0 ), the previous day (lag 1), and lag 01] in the temperatureadjusted approach to observe impacts from different exposure assessments for the study population; and 3) $\mathrm{O}_{3} 1 \mathrm{~h}$-max and $\mathrm{O}_{3} 24$ h-average with lag 01 exposure in the temperature-stratified approach to observe whether the modification effect of temperature on different ozone metrics was robust. Statistical analyses were conducted in the R Statistical Software (version 4.0.2, the Free Software Foundation's GNU Public License, Vienna, Austria). Statistical significance was considered at a $P$-value $<0.05$.

From 2013 to 2018, residents in the Beijing, Tianjin, Hebei and surrounding areas were exposed to a concentration of $\mathrm{O}_{3} 8 \mathrm{~h}$-average of $(95.2 \pm 61.4)$ $\mu \mathrm{g} / \mathrm{m}^{3}$. Approximately 11 deaths for non-accidental disease, 6 for cardiocerebrovascular disease, and 1 for respiratory disease per day per county were recorded (Table 1).

Based on the temperature-adjusted approach without considering interactions, a per $10 \mu \mathrm{g} / \mathrm{m}^{3}$ increase in exposure to $\mathrm{O}_{3} 8 \mathrm{~h}$-average would increase daily mortality risks of non-accidental $[\mathrm{PI}=0.15 \%$, 95\% Confidence Interval (CI): $0.06 \%, 0.24 \%]$, cardiocerebrovascular ( $\mathrm{PI}=0.20 \%, 95 \% \mathrm{CI}: 0.07 \%, 0.33 \%)$, and respiratory diseases $(\mathrm{PI}=-0.08 \%, 95 \% \mathrm{CI}$ : $-0.42 \%, 0.25 \%)$ in the Beijing, Tianjin, Hebei and surrounding areas. Based on temperature-stratified approach, relatively higher temperature ( $>75$ th 24 haverage temperature) significantly strengthened $\mathrm{O}_{3-}$ mortality associations, with a $0.57 \%$ risk increase of

TABLE 1. Summary for ambient $\mathrm{O}_{3}$, meteorological factors, and causes of death in the Beijing, Tianjin, Hebei and

\begin{tabular}{|c|c|c|c|c|}
\hline Variable & Mean士SD & $\mathbf{P}_{25}$ & $\mathbf{P}_{50}$ & $\mathbf{P}_{75}$ \\
\hline $\mathrm{O}_{3} 24$ h-average $\left(\mu \mathrm{g} / \mathrm{m}^{3}\right)$ & $56.3 \pm 38.7$ & 25.3 & 49.5 & 80.2 \\
\hline $\mathrm{O}_{3} 8 \mathrm{~h}$-average $\left(\mu \mathrm{g} / \mathrm{m}^{3}\right)$ & $95.2 \pm 61.4$ & 48.2 & 83.8 & 135.4 \\
\hline $\mathrm{O}_{3} 1 \mathrm{~h}-\max \left(\mu \mathrm{g} / \mathrm{m}^{3}\right)$ & $111.0 \pm 71.5$ & 59.7 & 95.0 & 155.0 \\
\hline Temperature $\left({ }^{\circ} \mathrm{C}\right)$ & $13.3 \pm 11.1$ & 2.8 & 14.6 & 23.4 \\
\hline Humidity (\%) & $0.6 \pm 0.2$ & 0.4 & 0.6 & 0.7 \\
\hline Non-accidental diseases & $11 \pm 8$ & 6 & 9 & 14 \\
\hline Cardio-cerebrovascular diseases & $6 \pm 4$ & 3 & 5 & 7 \\
\hline Respiratory diseases & $1 \pm 1$ & 0 & 1 & 2 \\
\hline
\end{tabular}
surrounding areas, 2013 to 2018.

Abbreviations: $S D=$ standard deviation; $P_{25}=25$ th percentile; $P_{50}=50$ th percentile; $P_{75}=75$ th percentile. 


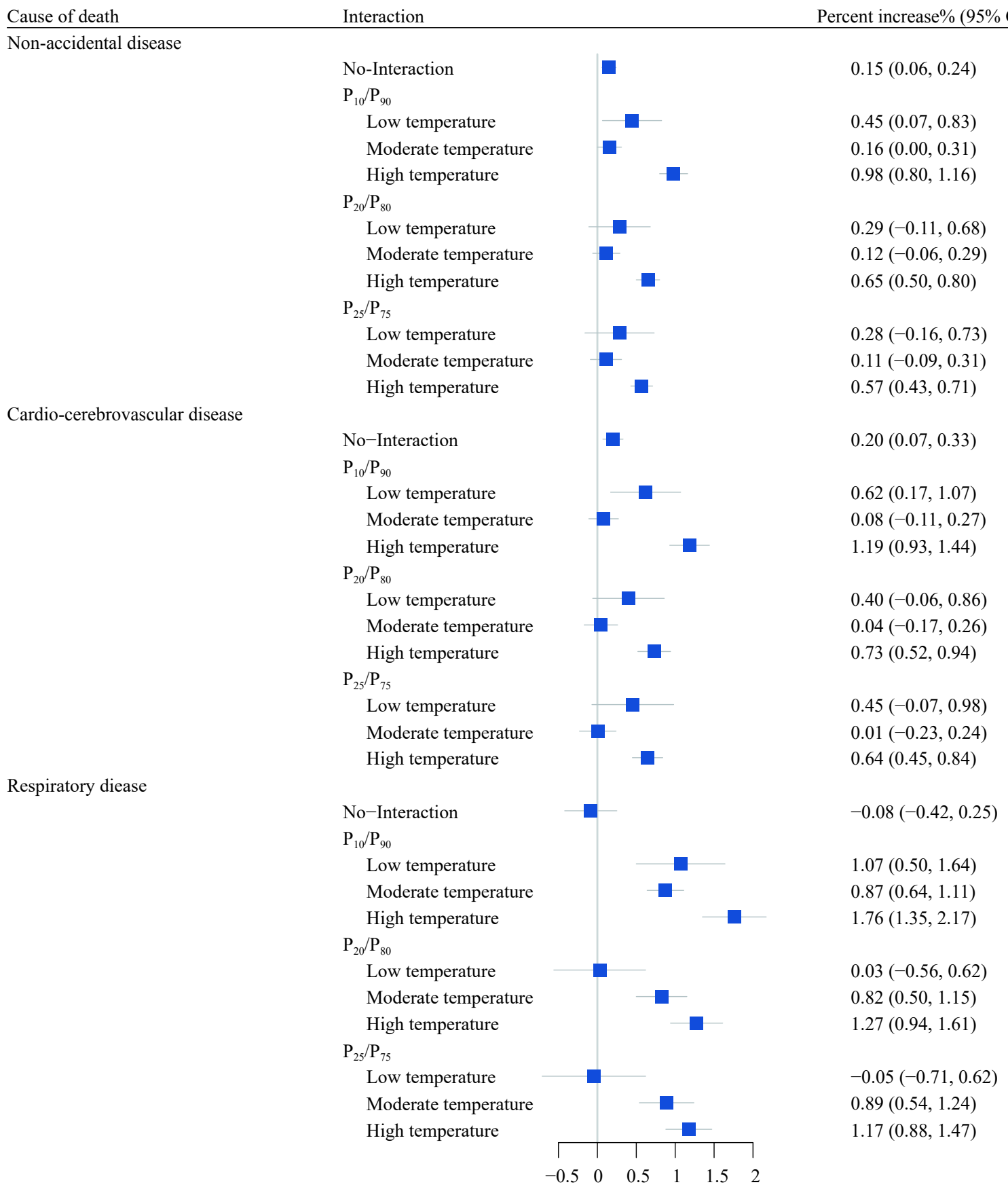

FIGURE 1. Mortality risk estimates associated with Lag 01 exposure of $\mathrm{O}_{3}$ by using the temperature-adjusted and temperature-stratified approach in the Beijing, Tianjin, Hebei and surrounding areas, 2013-2018.

Abbreviations: $P_{10}=10$ th percentile; $P_{90}=90$ th percentile; $P_{20}=20$ th percentile; $P_{80}=80$ th percentile; $P_{25}=25$ th percentile; $\mathrm{P}_{75}=75$ th percentile.

non-accidental disease, $0.64 \%$ risk increase of cardiocerebrovascular disease, and $1.17 \%$ risk increase of respiratory disease (Figure 1). Under extreme temperature ( $>90$ th 24 h-average temperature) modification, the associations between $\mathrm{O}_{3}$ and human mortality has further increased: a $0.98 \%$ risk increase of non-accidental disease, $1.19 \%$ risk increase of cardio-cerebrovascular disease, and $1.76 \%$ risk increase of respiratory disease (Figure 1). Moreover, extreme low temperature $(<10$ th $24 \mathrm{~h}$-average temperature) was also found to strengthen the acute effects of $\mathrm{O}_{3}$ on mortality (Figure 1).

Associations between short-term exposure to $\mathrm{O}_{3} 8$ h-average and mortality peaked at Lag 01 exposure. Analyses with different metrics of $\mathrm{O}_{3}$ exposure and more or less stringent time trends and relative 
TABLE 2. Percent increase $(95 \% \mathrm{Cl})$ in mortality risks associated with short-term exposure to $\mathrm{O}_{3}$ for sensitivity analysis by using the temperature-adjusted approach in the Beijing, Tianjin, Hebei and surrounding areas, 2013-2018. (\%)

\begin{tabular}{|c|c|c|c|c|c|c|}
\hline Pollutants & Lag & $d f_{\text {tem } / r h}=3, d f_{\text {time }}=6$ & $d f_{\text {tem } / r h}=5, d f_{\text {time }}=8$ & $d f_{\text {tem } / r h}=5, d f_{\text {time }}=7$ & $d f_{\text {tem/rh }}=3$ & $d f_{\text {tem/rh }}=3, d f_{\text {time }}=7$ \\
\hline \multirow{6}{*}{$\mathrm{O}_{3} 8 \mathrm{~h}$-average } & & 0.11 & 0.14 & 0.14 & 0.13 & 0.13 \\
\hline & Lag 0 & $(0.04,0.19)$ & $(0.06,0.22)$ & $(0.07,0.22)$ & $(0.05,0.21)$ & $(0.05,0.20)$ \\
\hline & & 0.03 & 0.07 & 0.06 & 0.05 & 0.04 \\
\hline & Lag 1 & $(-0.05,0.10)$ & $(-0.01,0.14)$ & $(-0.01,0.14)$ & $(-0.02,0.13)$ & $(-0.04,0.11)$ \\
\hline & & 0.09 & 0.15 & 0.14 & 0.13 & 0.10 \\
\hline & Lag 01 & $(-0.00,0.18)$ & $(0.06,0.24)$ & $(0.04,0.23)$ & $(0.04,0.22)$ & $(0.01,0.20)$ \\
\hline \multirow{6}{*}{$\mathrm{O}_{3} 1 \mathrm{~h}-\max$} & 1000 & 0.07 & 0.08 & 0.08 & 0.08 & 0.08 \\
\hline & Lag o & $(0.01,0.13)$ & $(0.03,0.14)$ & $(0.03,0.14)$ & $(0.02,0.14)$ & $(0.02,0.13)$ \\
\hline & 1001 & 0.06 & 0.08 & 0.07 & 0.07 & 0.06 \\
\hline & Lag 1 & $(-0.00,0.11)$ & $(0.02,0.13)$ & $(0.01,0.13)$ & $(0.01,0.12)$ & $(0.00,0.12)$ \\
\hline & Lag 01 & 0.10 & 0.13 & 0.12 & 0.12 & 0.10 \\
\hline & Lag o & $(0.02,0.17)$ & $(0.06,0.21)$ & $(0.05,0.20)$ & $(0.04,0.19)$ & $(0.03,0.18)$ \\
\hline \multirow{5}{*}{$\mathrm{O}_{3} 24 \mathrm{~h}$-average } & Lag 0 & $\begin{array}{c}0.13 \\
(0.01,0.24)\end{array}$ & $\begin{array}{c}0.14 \\
(0.02,0.25)\end{array}$ & $\begin{array}{c}0.17 \\
(0.06,0.28)\end{array}$ & $\begin{array}{c}0.13 \\
(0.02,0.24)\end{array}$ & $\begin{array}{c}0.15 \\
(0.04,0.26)\end{array}$ \\
\hline & & 0.12 & 0.16 & 0.17 & 0.14 & 0.14 \\
\hline & Lag 1 & $(0.01,0.23)$ & $(0.05,0.27)$ & $(0.06,0.28)$ & $(0.03,0.25)$ & $(0.03,0.25)$ \\
\hline & Lag 01 & 0.17 & 0.21 & 0.24 & 0.19 & 0.20 \\
\hline & Lag oI & $(0.03,0.30)$ & $(0.07,0.35)$ & $(0.10,0.38)$ & $(0.05,0.32)$ & $(0.06,0.34)$ \\
\hline
\end{tabular}

Note: $d f_{\text {tem/rh }}$ is the degree of freedom of natural smoothing function for temperature or relative humidity, $d f_{\text {time }}$ is the degree of freedom of natural smoothing function for the seasonal and time trends.

Abbreviation: $\mathrm{Cl}=$ confidence interval.

TABLE 3. Percent increase $(95 \% \mathrm{Cl})$ in mortality risks associated with short-term exposure to $\mathrm{O}_{3}$ for sensitivity analysis by using the temperature-stratified approach in the Beijing, Tianjin, Hebei and surrounding areas, 2013-2018. (\%)

\begin{tabular}{ccccc}
\hline Pollutants & Temperature & $\mathbf{P}_{10} / \mathbf{P}_{\mathbf{9 0}}$ & $\mathbf{P}_{\mathbf{2 0}} / \mathbf{P}_{\mathbf{8 0}}$ & $\mathbf{P}_{\mathbf{2 5}} / \mathbf{P}_{\mathbf{7 5}}$ \\
\hline \multirow{2}{*}{$\mathrm{O}_{3}$ 1 h-max } & Low & $0.30(-0.01,0.61)$ & $0.23(-0.09,0.54)$ & $0.24(-0.12,0.6)$ \\
& Moderate & $0.14(0.02,0.25)$ & $0.13(-0.01,0.27)$ & $0.13(-0.03,0.28)$ \\
& High & $0.81(0.66,0.97)$ & $0.55(0.43,0.68)$ & $0.49(0.37,0.61)$ \\
$\mathrm{O}_{3}$ 24 h-average & Low & $0.61(0.11,1.12)$ & $0.31(-0.24,0.86)$ & $0.32(-0.3,0.94)$ \\
& Moderate & $0.14(-0.11,0.4)$ & $0.08(-0.22,0.39)$ & $0.06(-0.28,0.41)$ \\
& High & $1.47(1.22,1.73)$ & $1.02(0.81,1.24)$ & $0.90(0.68,1.12)$ \\
\hline
\end{tabular}

Abbreviations: $\mathrm{Cl}=$ confidence interval; $\mathrm{P}_{10}=10$ th percentile; $\mathrm{P}_{90}=90$ th percentile; $\mathrm{P}_{20}=20$ th percentile; $\mathrm{P}_{80}=80$ th percentile; $\mathrm{P}_{25}=25$ th percentile; $\mathrm{P}_{75}=75$ th percentile.

humidity controlled by varying $d f s$ did not meaningfully change our findings (Table 2). For the three cutoffs of $\mathrm{P}_{10} / \mathrm{P}_{90}, \mathrm{P}_{20} / \mathrm{P}_{80}$, and $\mathrm{P}_{25} / \mathrm{P}_{75}$, the associations between the other two $\mathrm{O}_{3}$ metrics and morality were both increased under high temperature levels (Table 3). The extreme low temperature was found to only significantly modify the association between $\mathrm{O}_{3} 24$ h-average and mortality.

\section{DISCUSSION}

We used two time-series approaches to explore the effects of short-term exposure to $\mathrm{O}_{3}$ on mortality across temperature levels in the Beijing, Tianjin, Hebei and surrounding areas throughout a six-year period. Both the temperature-adjusted and temperaturestratified approaches indicated that short-term exposure to $\mathrm{O}_{3}$ was associated with an increased risk of mortality, and that the association was positive modified by high-temperature levels, especially modified by extreme heat. These findings were consistent with epidemiological evidence from several previous national-level studies (3,5,9). From an exposure standpoint, it may be because ground-level $\mathrm{O}_{3}$ is usually formed by photochemical reactions of precursor pollutants under the presence of light; as the temperature increases, the formation of $\mathrm{O}_{3}$ accelerates, and the emission of precursor pollutants increases, resulting in an increase in effect size of $\mathrm{O}_{3}$ along with increased pollution.

The study also found that the $\mathrm{O}_{3}$-mortality risks of cardiopulmonary diseases, as vulnerable diseases of air pollution, were further strengthened in the presence of high temperature. However, studies in some southern cities in China $(6-7)$ have not observed this modification effect. For example, a study conducted by Chen et al. in Jiangsu showed that $\mathrm{O}_{3}$ has a higher impact on death from cardiovascular diseases in a low temperature environment. The conflicting results indicated that the modification may vary considerately 
across different climatic regions. Represented by previous national studies conducted in the United States, Jhun et al. and Ren et al. consistently emphasized that the modification of temperature on the $\mathrm{O}_{3}$-mortality association varied across different regions $(3,9)$. In addition to different climates and characteristics of $\mathrm{O}_{3}$ pollution, various adaptive measures of local residents to mitigate exposure to $\mathrm{O}_{3}$ and temperature may be another reason for the regional differences (9). Residents in the regions of southern China may become less sensitive to the variability of $\mathrm{O}_{3}$ and temperature due to physical adaptation and higher air conditioning usage rates.

Experimental studies have observed that exposure to $\mathrm{O}_{3}$ can result in injuries (including cellular response, metabolic activity, and physiological changes in respiratory function) to the nasal cavity, trachea and proximal bronchi, central acinar bronchioles, and alveolar ducts (9). $\mathrm{O}_{3}$ inhaled through respiratory airways can also affect the regulation of the autonomic nervous system and then cause damage to human cardiovascular health. Meanwhile, although the mechanism of low temperature modification is not clear yet, marked changes in temperature can cause physiological stress and make individuals' physiological response vulnerable to toxic pollutants (10). This would be the possible reason why we found that the acute effects of a low $\mathrm{O}_{3}$ exposure on mortality for non-accidental and cardiopulmonary diseases were strengthened by extreme low temperature. What has caught our attention is that when a cold wave hits, even if $\mathrm{O}_{3}$ is at a low pollution level, it will have an adverse effect on health and should not be underestimated or ignored.

This study was subject to at least three limitations. First, the analytical methods used in our study can semi-quantitatively assess the difference in $\mathrm{O}_{3}$-related mortality risks across different temperature stratifications, but a more flexible statistical method is needed to quantify nonlinear modifications. Second, due to differences in climate patterns, the modification of temperature on the acute effect of $\mathrm{O}_{3}$ found here would not be applicable to other regions. We suggest that a more in-depth study of different climate regions in future studies. Finally, our study did not include information regarding the use of air conditioning or heating devices, which could influence the modification of temperature on $\mathrm{O}_{3}$-related mortality risks.

Our findings suggest that policymakers should pay attention to the synergistic effect between heat or extreme cold and $\mathrm{O}_{3}$ on human heath, as well as provide evidence for establishing an integrated early- warning system for protecting the public against both unsuitable temperature and air pollution.

Conflicts of interest: No conflicts of interest.

Funding: The National Key Research and Development Program of China (Grant number: 2016YFC0206500), the National Research Program for Key Issues in Air Pollution Control (Grant number: DQGG0401), and the Young Scholar Scientific Research Foundation of National Institute of Environmental Health, China CDC (Grant number: 2020YSRF_02).

doi: $10.46234 / \operatorname{ccdcw} 2021.234$

\# Corresponding author: Xiaoming Shi, shixm@chinacdc.cn.

\begin{abstract}
${ }^{1}$ China CDC Key Laboratory of Environment and Population Health, National Institute of Environmental Health, Chinese Center for Disease Control and Prevention, Beijing, China.
\end{abstract}

Submitted: October 26, 2021; Accepted: November 03, 2021

\section{REFERENCES}

1. Vicedo-Cabrera AM, Sera F, Liu C, Armstrong B, Milojevic A, Guo YM, et al. Short term association between ozone and mortality: global two stage time series study in 406 locations in 20 countries. BMJ 2020;368:m108. http://dx.doi.org/10.1136/BMJ.M108.

2. Yin P, Chen RJ, Wang LJ, Meng X, Liu C, Niu Y, et al. Ambient ozone pollution and daily mortality: a nationwide study in 272 Chinese cities. Environ Health Perspect 2017;125(11):117006. http://dx.doi.org/10. 1289/EHP1849.

3. Jhun I, Fann N, Zanobetti A, Hubbell B. Effect modification of ozonerelated mortality risks by temperature in 97 US cities. Environ Int 2014;73:128 - 34. http://dx.doi.org/10.1016/j.envint.2014.07.009.

4. Chen K, Wolf K, Breitner S, Gasparrini A, Stafoggia M, Samoli E, et al. Two-way effect modifications of air pollution and air temperature on total natural and cardiovascular mortality in eight European urban areas. Environ Int 2018;116:186 - 96. http://dx.doi.org/10.1016/j. envint.2018.04.021.

5. Shi WY, Sun QH, Du P, Tang S, Chen C, Sun ZY, et al. Modification effects of temperature on the ozone-mortality relationship: a nationwide multicounty study in China. Environ Sci Technol 2020;54(5):2859 68. http://dx.doi.org/10.1021/acs.est.9b05978.

6. Liu T, Li TT, Zhang YH, Xu YJ, Lao XQ, Rutherford S, et al. The short-term effect of ambient ozone on mortality is modified by temperature in Guangzhou, China. Atmos Environ 2013;76:59 - 67. http://dx.doi.org/10.1016/j.atmosenv.2012.07.011.

7. Chen K, Yang HB, Ma ZW, Bi J, Huang L. Influence of temperature to the short-term effects of various ozone metrics on daily mortality in Suzhou, China. Atmos Environ 2013;79:119 - 28. http://dx.doi.org/ 10.1016/j.atmosenv.2013.06.004.

8. Bauer DJ, Curran PJ. Probing interactions in fixed and multilevel regression: inferential and graphical techniques. Multivariate Behav Res 2005;40(3):373 - 400. http://dx.doi.org/10.1207/s15327906mbr4 $003 \_5$.

9. Ren CZ, Williams GM, Mengersen K, Morawska L, Tong SL. Temperature enhanced effects of ozone on cardiovascular mortality in 95 large US communities, 1987-2000: assessment using the NMMAPS data. Arch Environ Occup Health 2009;64(3):177 - 84. http://dx.doi. org/10.1080/19338240903240749.

10. Schwartz J. How sensitive is the association between ozone and daily deaths to control for temperature? Am J Respir Crit Care Med 2005;171(6):627-31. http://dx.doi.org/10.1164/rccm.200407-933OC. 